ORIGINAL ARTICLE

\title{
Is surgical ligation of patent ductus arteriosus necessary? The Western Australian experience of conservative management
}

\author{
J M Brooks, J N Travadi, S K Patole, D A Doherty, K Simmer
}

Arch Dis Child Fetal Neonatal Ed 2005;90:F235-F239. doi: 10.1136/adc.2004.057638

See end of article for authors' affiliations ................

Correspondence to: Dr Patole, Department of Neonatal Paediatrics, King Edward Memorial Hospital, Bagot Road, Subiaco, Western Australia 6008 . Sanjay.Patole@ health.wa.gov.au

Accepted August 2004

\begin{abstract}
Background: Surgical ligation of patent ductus arteriosus (PDA) is widely practised in preterm infants despite no clear evidence that this improves outcomes. Geographical isolation meant that ductal ligation was not an option in King Edward Memorial Hospital until recently.

Objective: A retrospective data analysis to test the hypothesis that outcomes of infants with persistent PDA were no worse than those of infants with no significant duct or a duct that closed after medical treatment. Patients and Methods: A total of 252 infants (gestation $\leqslant 28$ weeks) born between 1 January 2000 and 30 June 2002 were divided into three groups: group 1, no significant PDA ( $n=154$ ); group 2, significant PDA which closed after medical treatment $(n=65)$; group 3, significant PDA remaining patent after medical treatment $(n=33)$. A significant PDA was defined by a left atrium to aortic root ratio of $>1.4$ or a ductal diameter $>1.5 \mathrm{~mm}$ with a left to right shunt.

Results: Twenty four (10\%) infants died at median (interquartile range) 15.5 (9-35) days. After adjustment for gestational age, relative to group 1, the infants from group 3 were at a 4.02 times increased risk of death (95\% confidence interval 1.12 to 14.51 ). There was no significant difference between groups in the incidence of chronic lung disease, chronic lung disease or death, necrotising enterocolitis, intraventricular haemorrhage, duration of oxygen, or hospital stay.

Conclusion: Mortality was higher in infants with a persistent PDA, but other morbidities were not significantly different. A randomised trial is needed to determine whether surgical ligation will reduce mortality in such infants.
\end{abstract}

$\mathrm{P}$ atent ductus arteriosus (PDA) with a significant left to right shunt is associated with chronic lung disease (CLD), ${ }^{1}$ intraventricular haemorrhage $(\mathrm{IVH}),{ }^{23}$ and necrotising enterocolitis (NEC) $)^{45}$ in preterm neonates. The medical management of a haemodynamically significant PDA includes fluid restriction, diuretics, and intravenous prostaglandin synthetase inhibitors, such as indometacin. Indometacin, either as treatment or prophylaxis, has been shown to reduce the incidence of symptomatic PDA, the need for duct ligation, and the incidence of severe IVH. ${ }^{6}$ Surgical ligation is usually reserved for PDA refractory to medical management. Surgical ligation has been reported to have a low morbidity and has been proposed as a primary treatment of PDA and the treatment of PDA that responds poorly to indometacin. $^{8}$ A systematic review identified a single randomised controlled trial comparing surgical ligation and indometacin for closure of PDA in preterm infants with birth weight $<1750 \mathrm{~g}$. No significant differences in hospital stay, CLD, NEC, or IVH were noted. ${ }^{?}$

There are insufficient data and no clear evidence that surgical ligation of haemodynamically significant PDA is associated with improved outcomes. Historically, conservative management of PDA (waiting for spontaneous closure over several days or weeks while continuing ventilatory support) in preterm infants is reported to be associated with a high frequency of "bronchopulmonary dysplasia" in survivors. ${ }^{10}$ Given the advances in neonatal intensive care in the surfactant era, including the increased use of antenatal steroids, this may no longer be the case. King Edward Memorial Hospital for Women is the tertiary perinatal referral centre for the state of Western Australia, which spans 2.5 million $\mathrm{km}^{2}$ and serves a population of 1.8 million with 25000 births per annum. Lack of on site facilities for surgical ligation and geographical isolation from the nearest cardiac surgical centre (Melbourne, $3456 \mathrm{~km}$ and four hours flight time) meant that surgical ligation of PDA was not an option until recently. Our clinical experience suggested that the outcome of infants with persistent PDA was no worse than those of infants with no significant duct or a duct that closed after medical treatment. A retrospective data analysis was undertaken to test this hypothesis.

\section{PATIENTS AND METHODS}

All infants of $\leqslant 28$ weeks gestation born between 1 January 2000 and 30 June 2002 were included in the study. Outborn infants and those with congenital heart disease were excluded. Infants who died within the first 72 hours of life were also excluded, as even if there was a significant PDA, it was too short a time for closure to be achieved by prophylactic indometacin or surgery. After collecting basic and clinical data, infants were divided into three groups for further analysis: group 1, no PDA or no significant PDA; group 2, significant PDA, which closed after medical treatment; group 3, significant PDA, which remained patent after medical treatment.

Echocardiograms were obtained by either a consultant paediatric cardiologist or an echocardiography technician with subsequent report from a consultant paediatric cardiologist. Significant PDA was defined as echocardiogram findings of a left atrium to aortic root ratio of $>1.4^{7}$ or a ductal diameter $>1.5 \mathrm{~mm},{ }^{11}{ }^{12}$ associated with a left to right shunt into the main pulmonary artery from the PDA with low

Abbreviations: CLD, chronic lung disease; CRIB, clinical risk index for babies; IVH, intraventricular haemorrhage; NEC, necrotising enterocolitis; PDA, patent ductus arteriosus 
Table 1 Basic characteristics of all infants of $\leqslant 28$ weeks gestation born between 1 January 2000 and 30 June 2002

\begin{tabular}{|c|c|c|c|c|c|}
\hline & $\begin{array}{l}\text { All infants } \\
(n=252)\end{array}$ & $\begin{array}{l}\text { Group 1 } \\
(n=154)\end{array}$ & $\begin{array}{l}\text { Group 2 } \\
(n=65)\end{array}$ & $\begin{array}{l}\text { Group } 3 \\
(n=33)\end{array}$ & p Value \\
\hline Gestation* & $26(22-28)$ & $27(23-28)$ & $25(22-27)$ & $24(22-28)$ & $<0.001$ \\
\hline Birth weight $(\mathrm{g})^{*}$ & $893(410-1475)$ & $998(470-1475)$ & $775(410-1330)$ & $695(410-1260)$ & $<0.001$ \\
\hline SGA & $23(9 \%)$ & $12(8 \%)$ & $7(11 \%)$ & $4(12 \%)$ & 0.638 \\
\hline Male sex & $127(50 \%)$ & 79 (51\%) & $25(39 \%)$ & $23(70 \%)$ & 0.013 \\
\hline Multiple birth & $69(27 \%)$ & $36(23 \%)$ & $20(31 \%)$ & $13(39 \%)$ & $<0.001$ \\
\hline \multicolumn{6}{|l|}{ Antenatal steroids } \\
\hline$\geqslant$ one dose & 216 (87\%) & $135(88 \%)$ & $52(80 \%)$ & $29(88 \%)$ & 0.311 \\
\hline Complete† & $101(47 \%)$ & $69(51 \%)$ & $23(44 \%)$ & $9(31 \%)$ & 0.133 \\
\hline Any ventilation & $215(85 \%)$ & $118(77 \%)$ & 65 (100\%) & 32 (97\%) & $<0.001$ \\
\hline CRIB score* & $4(1-8)$ & $2(1-5)$ & $6(3-9)$ & $9(5-10)$ & $<0.001$ \\
\hline
\end{tabular}

*Values are median (range). The units for gestation are completed weeks.

tDefined as two doses 12 hours apart between 24 hours and 7 days before delivery.

Group 1, no significant PDA; group 2, significant PDA which closed after medical treatment; group 3, significant PDA remaining patent after medical treatment;

PDA, patent ductus arteriosus; SGA, small for gestational age, defined as weight $<10$ th centile for gestational age; CRIB, clinical risk index for babies.

velocity $(<1 \mathrm{~m} / \mathrm{s})^{12}{ }^{13}$ at end diastole. If an echocardiogram was unavailable, a PDA was labelled as "significant" on clinical grounds (systolic murmur, bounding pulses, hyperdynamic praecordium, wide pulse pressure, cardiomegaly, and pulmonary plethora on chest radiograph). A PDA was classified as closed on clinical and echocardiographic assessment over the first month of life.

Medical treatment of such significant PDA included fluid restriction, diuretics, and up to three courses of indometacin. Two different indometacin regimens were used during the study period; $100 \mu \mathrm{g} / \mathrm{kg} /$ day for five days or $200 \mu \mathrm{g} / \mathrm{kg} 12$ hourly for three doses. The decision as to which regimen to use was at the discretion of the consultant on service. Prophylactic indometacin was not used.

Outcomes assessed included CLD (defined as need for oxygen or respiratory support at 36 weeks postconceptual age, aiming for oxygen saturations $>96 \%$ ), IVH (grade 3 or $4),{ }^{14}$ proven NEC,${ }^{15}$ duration of hospital stay, and ventilatory support and survival with or without CLD.

\section{Statistical analysis}

Categorical data were summarised using frequency distributions, and continuous data were summarised using medians and interquartile ranges. Univariate analyses included $\chi^{2}$ and Fisher exact test, as appropriate, for categorical comparisons, and Mann-Whitney and Kruskal-Wallis tests for continuous outcomes. Univariate and multivariate logistic regression was performed to examine the risk factors for each of the clinical outcomes considered (such as CLD or death). Duration of ventilation, oxygen, and hospital stay were estimated using Kaplan-Meier probability estimates, and medians together with 25th and 75th centiles were determined for complement of survival times (transfers to another institution and deaths were censored for this analysis). Analysis of duration of

Table 2 Indometacin use during study period

\begin{tabular}{lll}
\hline & $\begin{array}{l}\text { Group 2 } \\
(\mathbf{n}=65)\end{array}$ & $\begin{array}{l}\text { Group 3 } \\
(\mathbf{n}=33)\end{array}$ \\
\hline $\begin{array}{lll}\text { Received indometacin } \\
\text { Indometacin regimen }\end{array}$ & $58(89)$ & $31(94)$ \\
$\quad \begin{array}{ll}\text { Five doses } \\
\text { Three doses }\end{array}$ & $50(77)$ & $28(85)$ \\
$\begin{array}{l}\text { Treatment stopped because of adverse effects } \\
\text { Multiple number of courses }\end{array}$ & $9(12)$ & $3(9)$ \\
& $12(18)$ & $4(12)$ \\
\hline
\end{tabular}

Values are number (\%).

Group 2, significant patent ductus arteriosus (PDA) which closed after medical treatment; group 3, significant PDA remaining patent after medical treatment. ventilation, oxygen requirement, and hospital stay was carried out using the Cox proportional hazards regression model. SPSS statistical software was used for data analysis. All hypothesis tests were two sided, and a $\mathrm{p}<0.05$ was considered significant.

\section{RESULTS}

A total of 284 infants of $\leqslant 28$ weeks gestation were admitted to the neonatal unit between 1 January 2000 and 30 June 2002. The outcomes for 252 infants were analysed. Thirty two infants were excluded from the analysis (13 were outborn, one had complex congenital heart disease, and 18 died within the first 72 hours of life). Ninety eight cases (39\%) of significant PDA were noted (96 were diagnosed by echocardiography and two were diagnosed on clinical grounds). Of the 98 infants who presented with a significant duct, PDA was successfully closed with medical treatment in 65 and remained open in $33(34 \%)$. Table 1 shows descriptive statistics for the entire group and groups stratified by the PDA status. The infants with significant PDA that remained open after medical treatment were born at earlier gestations $(p<0.001)$, had lower birth weight $(p<0.001)$, and had higher clinical risk index for babies (CRIB) scores $^{16}$ $(\mathrm{p}<0.001)$.

Eighty nine infants (91\%) with a significant PDA received indometacin: seventy eight $(88 \%)$ of these infants were started on a five dose regimen, 11 infants $(12 \%)$ received a three dose regimen, and treatment was stopped prematurely in 13 infants (15\%) because of adverse effects of indometacin. The median age at start of treatment was 5 days (interquartile range 2-8, range 1-24). A maximum of three courses of indometacin were administered, with 10 infants (30\%) in group 3 receiving multiple courses compared with $12(18.5 \%)$ in group 2 (table 2 ). No significant effects of multiple courses of indometacin were evident for any of the outcomes considered.

Twenty four infants died $(10 \%)$, with the age of death ranging between 4 and 306 days (median 15.5, interquartile range 9-35). Median gestational age for these infants was 25 weeks (range 23-28). Six of these infants (4\%) were from group 1 , seven from group $2(11 \%)$, and 11 from group 3 (33\%). Mortality was significantly different between groups in a univariate groups comparison, and remained significantly different when gestational age and CRIB score were controlled for (table 3). Relative to the infants in group 1, the infants in group 3 were at a higher risk of death (odds ratio $(\mathrm{OR})=4.02, \mathrm{p}=0.033)$. Mortality did not differ significantly between groups 2 and $\mathrm{l}(\mathrm{OR}=1.13, \mathrm{p}=$ 0.849 ). The causes of death ranged from extreme prematurity and lung hypoplasia to grade 4 IVH and severe NEC (table 4). 
Table 3 Dichotomous clinical variables adjusted for gestational age and clinical risk index for babies (CRIB) score

\begin{tabular}{|c|c|c|c|c|}
\hline \multirow[b]{2}{*}{ Outcome } & \multirow{2}{*}{$\begin{array}{l}\text { No of } \\
\text { diagnoses (\%) }\end{array}$} & \multicolumn{2}{|c|}{ Adjusted OR } & \multirow[b]{2}{*}{ p Value } \\
\hline & & OR & $95 \% \mathrm{Cl}$ & \\
\hline Death & $24(10)$ & & & \\
\hline PDA insignificant & $6(4)$ & 1.00 & & \\
\hline PDA closed & $7(11)$ & 1.13 & 0.31 to 4.15 & 0.849 \\
\hline PDA open & $11(33)$ & 4.02 & 1.12 to 14.51 & 0.033 \\
\hline Death/CLD* at 36 weeks & $143(57)$ & & & \\
\hline PDA insignificant & $68(44)$ & 1.00 & & \\
\hline PDA closed & 47 (72) & 1.22 & 0.55 to 2.66 & 0.627 \\
\hline PDA open & $28(85)$ & 1.67 & 0.50 to 5.69 & 0.400 \\
\hline$C L D^{*}(n=237)$ & $121(51)$ & & & \\
\hline PDA insignificant & $64(43)$ & 1.00 & & \\
\hline PDA closed & $40(67)$ & 1.13 & 0.53 to 2.35 & 0.778 \\
\hline PDA open & $7(63)$ & 0.58 & 0.20 to 1.67 & 0.315 \\
\hline NEC & $17(7)$ & & & \\
\hline PDA insignificant & $8(5)$ & 1.00 & & \\
\hline PDA closed & $5(8)$ & 1.10 & 0.31 to 3.94 & 0.888 \\
\hline PDA open & $4(12)$ & 1.57 & 0.36 to 6.83 & 0.546 \\
\hline IVH grade $3-4$ & $18(7)$ & & & \\
\hline PDA insignificant & $6(4)$ & 1.00 & & \\
\hline PDA closed & $8(12)$ & 1.53 & 0.44 to 5.28 & 0.503 \\
\hline PDA open & $4(12)$ & 1.05 & 0.23 to 4.79 & 0.954 \\
\hline
\end{tabular}

Data were evaluated using logistic regression analysis. Adjusted ORs were obtained in a multivariate logistic regression. No significant effects of sex and intrauterine growth retardation were found in addition to gestational age at delivery and CRIB score.

${ }^{*} \mathrm{CLD}$ limited to the infants alive at 36 weeks postconceptional age.

CLD, Chronic lung disease; IVH, intraventricular haemorrhage; NEC, necrotising enterocolitis; PDA, patent ductus arteriosus; OR, odds ratio.

No clear association could be derived between cause of death and ductal patency.

CLD developed in 127 (51\%) of the 237 infants who survived until 36 weeks postconceptional age. A higher proportion of infants from group 3 (PDA open) developed CLD than from group 1 ( $63 \% \vee 43 \%)$. This difference was not significant after gestational age at delivery had been controlled for (table 3). Similar findings were observed when a composite outcome of CLD at 36 weeks postconceptional age or death was examined (table 3 ).

Proven NEC was diagnosed in 17 infants (7\%). The incidence was not different in the three groups after adjustment for gestational age. Similarly, the overall incidence for severe IVH (grade 3-4) was 7\%, with no significant differences in the risk of developing IVH between groups (table 3$)$. Five infants $(2 \%)$ were diagnosed with

Table 4 Causes of death

\begin{tabular}{|c|c|c|c|c|}
\hline Study group & Gestation & $\begin{array}{l}\text { Birth } \\
\text { weight (g) }\end{array}$ & Cause of death & Age at death (days) \\
\hline \multirow[t]{6}{*}{ Group $1(n=6)$} & 24 & 645 & Grade 4 IVH & 9 \\
\hline & 27 & 1225 & Multiorgan failure, bilateral subdural haemorrhage & 5 \\
\hline & 25 & 785 & Sepsis & 306 \\
\hline & 23 & 535 & $\mathrm{HMD}, \mathrm{PIE}$, extreme prematurity & 4 \\
\hline & 26 & 735 & Respiratory failure secondary to pulmonary hypoplasia & 150 \\
\hline & 28 & 1150 & NEC and cerebral ischaemia & 36 \\
\hline \multirow[t]{7}{*}{ Group $2(n=7)$} & 28 & 1190 & Gram negative septicaemia & 10 \\
\hline & 23 & 650 & Candida septicaemia with DIC & 18 \\
\hline & 25 & 835 & Cardiac tamponade secondary to TPN effusion & 55 \\
\hline & 23 & 665 & Pneumonia and CLD & 14 \\
\hline & 25 & 890 & Perforated NEC & 10 \\
\hline & 23 & 670 & Perforated NEC with peritonitis & 13 \\
\hline & 25 & 410 & Perforated NEC with multiorgan failure & 12 \\
\hline \multirow[t]{11}{*}{ Group $3(n=11)$} & 23 & 640 & Grade 4 IVH & 27 \\
\hline & 23 & 490 & Overwhelming sepsis and cardiac failure & 17 \\
\hline & 23 & 570 & Systemic candidiasis & 23 \\
\hline & 23 & 700 & Pneumonia, extreme prematurity & 28 \\
\hline & 25 & 550 & $\mathrm{PPHN}$ and severe PIE & 12 \\
\hline & 23 & 505 & Pulmonary haemorrhage & 6 \\
\hline & 23 & 645 & NEC, prematurity & 5 \\
\hline & 25 & 620 & Perforated NEC with multiorgan failure & 33 \\
\hline & 24 & 740 & Perforated NEC & 37 \\
\hline & 27 & 410 & Perforated NEC with multiorgan failure & 41 \\
\hline & 27 & 1095 & HMD and pneumothoraces & 9 \\
\hline
\end{tabular}

Gestation is given as completed weeks.

Group 1, no significant PDA; group 2, significant PDA which closed after medical treatment; group 3, significant PDA remaining patent after medical treatment; $\mathrm{CLD}$, chronic lung disease; IVH, intraventricular haemorrhage; NEC, necrotising enterocolitis; PDA, patent ductus arteriosus; HMD, hyaline membrane disease; $\mathrm{PIE}$, pulmonary interstitial emphysema; DIC, disseminated intravascular coagulation; total parenteral; PPHN, persistent pulmonary hypertension of the newborn. 
Table 5 Continuous clinical variables adjusted for gestational age and clinical risk index for babies (CRIB) score

\begin{tabular}{|c|c|c|c|c|}
\hline \multirow[b]{2}{*}{ Outcome } & \multirow{2}{*}{$\begin{array}{l}\text { Median } \\
(Q 1-Q 3)^{*}\end{array}$} & \multicolumn{2}{|c|}{ Adjusted HR } & \multirow[b]{2}{*}{ p Value } \\
\hline & & HR & $95 \% \mathrm{Cl}$ & \\
\hline Duration of ventilation & $25(7-53)$ & & & \\
\hline PDA insignificant & $14(4-31)$ & 1.00 & & \\
\hline PDA closed & $37(20-62)$ & 0.86 & 0.63 to 1.19 & 0.336 \\
\hline PDA open & $60(41-75)$ & 0.70 & 0.44 to 1.11 & 0.130 \\
\hline Duration of oxygen & $62(20-103)$ & & & \\
\hline PDA insignificant & 48 (20-103) & 1.00 & & \\
\hline PDA closed & $90(76-103)$ & 0.89 & 0.63 to 1.27 & 0.526 \\
\hline PDA open & $85(44-120)$ & 1.20 & 0.73 to 1.98 & 0.476 \\
\hline Hospital stay & $91(71-119)$ & & & \\
\hline PDA insignificant & $80(65-100)$ & 1.00 & & \\
\hline PDA closed & $111(8-127)$ & 0.75 & 0.53 to 1.07 & 0.177 \\
\hline PDA open & 111 (94-159) & 0.85 & 0.48 to 1.50 & 0.579 \\
\hline \multicolumn{5}{|c|}{$\begin{array}{l}\text { Analysis was performed using Cox proportional hazards regression. Adjusted HRs were obtained in a multivariate } \\
\text { regression model. In all regression models, data for infants who died ( } n=24 \text {, table } 3 \text { ) or were transferred (group } \\
1,2,3: n=3,1,3 \text { respectively) were censored. No significant effects of sex and intrauterine were found in } \\
\text { addition to gestational age at delivery and CRIB score. } \\
\text { *Q1 and Q3 list the number of days that } 25 \text { th and } 75 \text { th centiles of infants remained on ventilation, oxygen, or } \\
\text { stayed in the hospital. } \\
\text { PDA, Patent ductus arteriosus; HR, hazard ratio. }\end{array}$} \\
\hline
\end{tabular}

periventricular leucomalacia, and associations with the PDA status were not analysed because of the small sample size.

The duration of ventilation was longer (60 v 14 days) in infants with a persistent duct (group 3) than in infants from group 1. However, this difference was not significant after adjustment for gestational age and CRIB score $(p=0.13)$. The durations of oxygen supplementation and hospital stay were also not significantly different between groups (table 5).

All surviving infants were followed over the first 12 months of life by neonatologists. One infant (group 3) was referred to Princess Margaret Hospital for surgical ligation at 8 weeks of age and was subsequently discharged home.

\section{DISCUSSION}

Our results indicate that the risk of death may be significantly higher in infants with persistent patency of the duct. Early surgery may thus be of benefit in reducing mortality in this group of infants. We found no evidence that persistent patency of the duct was associated with CLD, IVH, or NEC. Mortality and morbidity in our unit is comparable to national data: CLD 52\% v 45\%, grade 3-4 IVH 7\% v 12\%, NEC $6.7 \%$ v $6.3 \%$, and mortality $16 \%$ v 20\% $\leqslant 28$ weeks gestation, Western Australia $v$ Australian and New Zealand Neonatal Network. ${ }^{15}$ The incidence of CLD appears somewhat higher because of Western Australia having a higher oxygen saturation target $\left(>95 \% \mathrm{SpO}_{2}\right)$ for infants with CLD than other centres.

Evidence on the effect of PDA and its closure on respiratory status in preterm neonates is not clear. Stefano et al, ${ }^{17}$ Yeh et $a{ }^{18}$ Gerhardt and Bancalari, ${ }^{19}$ and Szymankiewicz et $a{ }^{20}$ have all reported improved lung function after closure of PDA after indometacin ${ }^{17} 18$ or surgical ligation..$^{12}$ Farstad and Bratlid, ${ }^{21}$ however, found no difference in compliance with ductal closure in infants with respiratory distress syndrome. Van Woerkom et al, ${ }^{22}$ in their analysis of very low birthweight infants who underwent PDA ligation, reported no short term benefits in mean airway pressure, fractional inspired oxygen, oxygenation, or ventilation index. In fact, they noted a trend towards adverse outcome after controlling for the variables of sex, gestational age, birth weight, and age at ligation. Carboni and Ringel $^{23}$ in their retrospective analysis of echocardiograms in infants $<35$ weeks gestation found that the presence of PDA after two weeks did not relate to duration of ventilation, oxygen therapy, or hospital stay. Also, a late closure of PDA in a subgroup of 11 infants did not appear to affect these variables. They hypothesised that closure of PDA beyond the second week may not improve the infants' respiratory status. The lack of difference in durations of ventilation, oxygen therapy, and hospital stay between infants in group 3 compared with infants in group 2 in our study may also be related to a late postnatal age at the time of ductal closure.

Larger PDA diameters have been shown to be associated with all grades of IVH. ${ }^{2}$ Prophylactic indometacin is known to decrease the incidence of symptomatic PDA and grade 3-4 IVH. ${ }^{24-26}$ However, whether the effect of prophylactic indometacin on IVH is secondary to PDA closure per se is not clear. PDA is also a significant risk factor for the development of NEC. ${ }^{45}{ }^{27}$ Cassady et $a^{28}$ in a randomised controlled trial showed a significant reduction in the incidence of NEC in very low birthweight infants when a PDA was ligated within 5 days of birth compared with infants where the duct was either ligated late or not at all. The lack of difference in the incidence of IVH or NEC between the three groups in our study may be related to inadequate power to test these variables.

In summary, our results indicate that mortality is significantly higher in infants with persistent PDA but that respiratory morbidity, IVH, and NEC are unaffected by patency of the duct. Thus routine surgical ligation of a duct refractory to medical treatment may not decrease CLD or affect morbidities such as IVH and NEC in preterm infants. The clinical significance of higher mortality in infants with a persistent PDA is uncertain given the wide confidence intervals and the lack of a clear relation between PDA and causes of death. A randomised controlled trial of surgical ligation of ductus patent after medical treatment is needed to confirm our findings. The design of any such trial needs to carefully consider the difference in baseline risk between the reference population and those infants randomised to surgical ligation or no ligation.

\section{Authors' affiliations}

J M Brooks, J N Travadi, S K Patole*, K Simmer*, Women's and Children's Health Service, Western Australia and *University of Western Australia

D A Doherty, Women and Infants Research Foundation and University of Western Australia

Competing interests: none declared 


\section{REFERENCES}

1 Redline RW, Wilson-Costello D, Hack M. Placental and other perinatal risk factors for chronic lung disease in very low birth weight infants. Pediatr Res 2002;52:713-19.

2 Evans N, Kluckow M. Early ductal shunting and intraventricular haemorrhage in ventilated preterm infants. Arch Dis Child Fetal Neonatal Ed 1996;75:F183-6.

3 Dykes FD, Lazzara A, Ahlmann P, et al. Intraventricular haemorrhage: a prospective evaluation of etiopathogenesis. Pediatrics 1980;66:42-9.

4 Ryder RW, Shelton JD, Quinan D. Necrotising enterocolitis: a prospective multicenter investigation. Am J Epidemiol 1980;112:113-23.

5 Noerr B. Current controversies in the understanding of necrotizing enterocolitis. Part 1. Adv Neonatal Care 2003;3:107-20.

6 Fowlie PW, Davis PG. Prophylactic indometacin for preterm infants: a systematic review and meta-analysis. Arch Dis Child Fetal Neonatal Ed 2003:88:F464-6.

7 McGuire W, Fowlie PW. Treating extremely low birthweight infants with prophylactic indometacin. Evidence for short-term benefits only. BMJ 2002;324:60-1.

8 Little DC, Pratt TC, Blalock SE, et al. Patent ductus arteriosus in micropreemies and full-term infants: the relative merits of surgical ligation versus indometacin treatment. J Pediatr Surg 2003;38:492-6.

9 Malviya M, Ohlsson A, Shah S. Surgical versus medical treatment with cyclooxygenase inhibitors for symptomatic patent ductus arteriosus in preterm infants. Cochrane Database Syst Rev 2003;(3):CD003951.

10 Lelong Tissier MC, Benoit A, Dehan M, et al. Conservative management of patent ductus arteriosus in preterm infants. Intensive Care Med 1979;5:33-6.

11 Kluckow M, Evans N. Early echocardiographic prediction of symptomatic patent ductus arteriosus in preterm infants undergoing mechanical ventilation. Pediatr 1995; 127:774-9.

12 Skinner J, Alverson D, Hunter S, eds. Echocardiography for the neonatologist. London: Churchill Livingstone, 2000.

13 Skinner J. Diagnosis of patent ductus arteriosus. Semin Neonatol $2001 ; 6: 49-61$

14 Papile LA, Munsick-Bruno G, Schaefer A. Relationship of cerebral intraventricular hemorrhage and early childhood neurologic handicaps. J Pediatr 1983;103:273-7.

15 Donoghue D, the ANZNN. The report of the Australian and New Zealand Neonatal Network, 2000. Sydney: ANZNN, 2002.
16 The International Neonatal Network. The CRIB (Clinical Risk Index for Babies) score: a tool for assessing initial neonatal risk and comparing performance of neonatal intensive care units. Lancet 1993;342:193-8.

17 Stefano JL, Abbasi S, Pearlman SA, et al. Closure of the ductus arteriosus with indometacin in ventilated neonates with respiratory distress syndrome. Effects on pulmonary compliance and ventilation. Am Rev Respir Dis $1991 ; 143: 236-9$

18 Yeh TF, Thalji A, Luken L, et al. Improved lung compliance following indometacin therapy in premature infants with persistent ductus arteriosus. Chest 1981;80:698-700.

19 Gerhardt T, Bancalari E. Lung compliance in newborns with patent ductus arteriosus before and after surgical ligation. Biol Neonate 1980;38:96-105

20 Szymankiewicz M, Hodgman JE, Siassi B, et al. Mechanics of breathing after surgical ligation of patent ductus arteriosus in newborns with respiratory distress syndrome. Biol Neonate 2004;85:32-6.

21 Farstad T, Bratlid D. Pulmonary effects of closure of patent ductus arteriosus in premature infants with severe respiratory distress syndrome. Eur J Pediatr 1994; 153:903-5.

22 Van Woerkom R, Govindaswami B, Cleary J, et al. Patent ductus arteriosus ligation in very low birthweight infants: is there benefit? Pediatr Res 2001:A32.

23 Carboni MP, Ringel RE. Ductus arteriosus in premature infants beyond the second week of life. Pediatr Cardiol 1997;18:372-5.

24 Fowlie PW. Intravenous indometacin for preventing mortality and morbidity in very low birth weight infants. Cochrane Database Syst Rev 2000;(2):CD000174.

25 Schmidt B, Davis P, Moddemann D, et al. Trial of indometacin prophylaxis in preterms investigators. Long-term effects of indometacin prophylaxis in extremely-low-birth-weight infants. N Engl J Med 2001;344:1966-72.

26 Coombs RC, Morgan MEl, Durbin GM, et al. Gut blood flow velocities in the newborn: effects of patent ductus arteriosus and parenteral indometacin. Arch Dis Child 1990;65:1067-71

27 Meyers R, Alpan G, Lin E, et al. Patent ductus arteriosus, indometacin and intestinal distension: effects on intestinal blood flow and oxygen consumption. Pediatr Res 1991;29:569-74.

28 Cassady G, Crouse DT, Kirklin JW, et al. A randomized, controlled trial of very early prophylactic ligation of the ductus arteriosus in babies who weighed $1000 \mathrm{~g}$ or less at birth. N Engl J Med 1989;320:1511-16. 